\title{
Assessment of the severity of nausea and vomiting among women during pregnancy vs. selected risk factors
}

\begin{abstract}
Introduction. It is estimated that $90 \%$ of pregnant women suffer from nausea and vomiting (NVP). The severity of NVP may vary and the first symptoms tend to appear between the $4^{\text {th }}$ and $9^{\text {th }}$ week of pregnancy, reaching their peak around $7^{\text {th }}-12^{\text {th }}$ week and disappear around $16^{\text {th }}-20^{\text {th }}$ week of pregnancy. The etiology of both nausea and vomiting is yet to be discovered, yet there is a number of factors that may contribute to it. These symptoms usually accompany the increase of human chorionic gonadotropin (hCG) and most intensive ailments associated to the highest rate of this hormone appear around the $10^{\text {th }}$ week of pregnancy.

Aim. Assessing the severity of nausea and vomiting in pregnant women and selected risk factors.

Material and methods. The study group consisted of 150 women hospitalized in the Independent Public Teaching Hospital No 4 in Lublin. The head of the Department of Obstetrics and Perinatology Agreement has agreed for the studies to be conducted. The authors used a research tool named modified scale Pregnancy Unique Quantification of Emesis which allowed to investigate the incidence and severity of nausea and vomiting during pregnancy. Demographic data and information on the conditions of nausea and vomiting in pregnancy were collected using a questionnaire survey of the authors' own making. Database and statistical tests were conducted using 10.0 STATISTICA software (StatSoft, Poland).

Results. The analysis revealed that 108 women $(72.00 \%)$ experienced nausea or vomitting during pregnancy. Taking into consideration the first trimester of pregnancy, a moderate severity of nausea and vomiting (NVP) occurred with an average of $6.51 \pm 3.17$ pt. It was found that 82 respondents had light intensity of NVP, whereas 68 moderate. In the second trimester an average intensity of nausea and vomiting (NVP) came to $4.82 \pm 2.45 \mathrm{pt}$, i.e. 117 women had mild symptoms while 33 had moderate symptoms. During the third trimester NVP severity dropped to $3.88 \pm 1.67$. The majority of respondents stated that nausea and vomiting was of light intensity $(92.00 \%)$, while $8 \%$ declared that it was moderate.

Conclusions. The severity of nausea and/or vomiting varies in the course of pregnancy, with significantly more moderate than mild symptoms occurring in the first compared to other trimesters of gestation. The degree of the severity of NVP in the third trimester of pregnancy is significantly affected by risk factors occurring before pregnancy (migraine headache, nausea or vomiting), and co-morbidities. However, the number of pregnancies, the fact whether the pregnancy was planned or not, motion sickness do not have major significance in this matter.
\end{abstract}

Keywords: nausea, vomiting, pregnancy.

DOI: $10.1515 /$ pjph-2015-0054

\section{INTRODUCTION}

It is estimated that $90 \%$ of pregnant women suffer from nausea and vomiting (NVP). The severity of NVP may vary and the first symptoms tend to appear between the $4^{\text {th }}$ and $9^{\text {th }}$ week of pregnancy, reaching their peak around $7^{\text {th }}-12^{\text {th }}$ week and disappear around $16^{\text {th }}-20^{\text {th }}$ week of pregnancy. However, around $10 \%$ of women are affected by the complaints during the whole pregnancy. The etiology of both nausea and vomiting is yet to be discovered, yet there is a number of factors that may contribute to it. The hypothesis about the hormonal changes caused by the development of the fetus seems to be the most popular. It is believed that mother's placental hormones are to be blamed for pregnant women oversensitivity to smells, as well as nausea or vomiting. These symptoms usually accompany the increase of human chorionic gonadotropin (hCG) and most intensive ailments associated to the highest rate of this hormone appear around the $10^{\text {th }}$ week of pregnancy.

\section{AIM}

An attempt to assess the severity of nausea and vomiting in relation to selected risk factors among women in pregnancy.

\section{MATERIAL AND METHODS}

150 pregnant inpatients were recruited from the Obstetrics and Perinatology Clinic. in the Independent Public Teaching Hospital No 4 in Lublin. The head of the Clinic has granted permission for conducting the study. First, we conducted a pilot study to verify the research tools. 30 pregnant women were analyzed at this point. The results confirmed that research tools were constructed correctly. 
The age range of women was 18-42, with the average age $29.71 \pm 5.26$ years. Most subjects were city residents $(n=105$; $70.00 \%)$, had higher education $(\mathrm{n}=88 ; 58.67 \%)$, were married $(\mathrm{n}=141 ; 94.00 \%)$ and assessed their financial situation as good $(\mathrm{n}=101 ; 67.33 \%)$.

The analyses were performed using the Pregnancy Unique Quantification of Emesis research tool. The scoring system includes 3 questions, all related to concerning the frequency and intensity of nausea and vomiting during pregnancy. To receive better and accurate results, all questions have been assigned to each trimester of pregnancy.

Demographic data as well as additional information concerning the appearance of nausea and vomiting among pregnant women were collected, using a questionnaire of the authors' own making.

A statistical analysis of the research results was conducted. The values of measurable parameters have been depicted with average values, median and standard deviation; non-measurable parameters have been shown with numerousness and proportion. For measurable properties the normal distribution of analyzed parameters has been evaluated with a W. ShapiroWilk test.

The U Mann-Whitney test was used for comparing two independent groups. In case there were more than two groups, the authors used the Kruskal-Wallis test.

A homogeneity $\mathrm{Ch} 2$ test has been used to detect differences between the study groups, concerning the relation to unlinked quality properties.

Statistical significance of $\mathrm{p}<0.05$ has been set to reveal some important discrepancies on the one hand or other relations on the other. The database and statistical analysis has been compiled and conducted using the STATISTICA 10.0 software (StatSoft, Polska).

\section{RESULTS}

The analysis revealed that 108 women $(72.00 \%)$ experienced nausea or vomiting during pregnancy. On average, these symptoms appeared around $7.45 \pm 3.47$ week of pregnancy.

Taking into consideration the first trimester of pregnancy, a moderate severity of nausea and vomiting (NVP) occurred with an average of $6.51 \pm 3.17 \mathrm{pt},(\mathrm{Me}=6.00)$. It was found that $82(54.67 \%)$ respondents had light intensity of NVP, whereas $68(45.33 \%)$ moderate. In the second trimester an average intensity of nausea and vomiting (NVP) came to $4.82 \pm 2.45$ pt, (Me 3.00), i.e. 117 (78.00\%) women had mild symptoms while $33(22.00 \%)$ had moderate symptoms. During the third trimester NVP severity dropped to $3.88 \pm 1.67$, (Me 3.00). The majority of respondents stated that nausea and vomiting was of light intensity $(\mathrm{n}=138 ; 92.00 \%)$, while $8 \%(\mathrm{n}=12)$ declared that it was moderate.

A more detailed illustration of the severity of nausea and vomiting in different trimesters of pregnancy is presented in Table 1 .

TABLE 1. Assessment of the severity of NVP in three trimesters of pregnancy.

\begin{tabular}{lccccccc}
\hline \hline $\begin{array}{l}\text { Symptoms } \\
\text { severity }\end{array}$ & \multicolumn{1}{c}{$\mathbf{1}^{\text {st }}$ trimester } & \multicolumn{2}{c}{$\mathbf{2}^{\text {nd }}$ trimester } & \multicolumn{2}{c}{$\mathbf{3}^{\text {rd }}$ trimester } & \multirow{2}{*}{$\begin{array}{c}\text { Statistical } \\
\text { analysis }\end{array}$} \\
\cline { 2 - 7 } & $\mathbf{n}$ & $\mathbf{\%}$ & $\mathbf{n}$ & $\mathbf{\%}$ & $\mathbf{n}$ & $\mathbf{\%}$ & \\
\hline Mild & 82 & 54.67 & 117 & 78.00 & 138 & 92.00 & $\mathrm{Chi}^{2}=147.38 ;$ \\
Moderate & 68 & 45.33 & 33 & 22.00 & 12 & 8.00 & $\mathrm{p}<0.00001^{*}$ \\
\hline
\end{tabular}

The statistical analysis revealed that during the first trimester of pregnancy moderate symptoms of NVP were more likely to occur $\left(\mathrm{Chi}^{2}=147.38 ; \mathrm{p}<0.00001\right)$ than mild $(45.33 \%)$ in comparison to the second trimester $(22.00 \%)$ and third trimester $(8.00 \%)$. A totally different tendency was discovered in case of mild symptoms.

It was the first pregnancy for 76 women (50.67\%), for 44 $(29.33 \%)$ it was a second one and for 30 of them $(20.00 \%)$ it was third or more. During previous pregnancies the majority of multigravidas suffered from nausea $(n=49 ; 66.22 \%)$ or vomiting $(\mathrm{n}=37,50.00 \%)$. That particular pregnancy was planned by 109 women (72.67\%). 43 respondents $(28.67 \%)$ declared being affected by some kind of co-morbidities. 103 women $(68.67 \%)$ had migraine headaches before pregnancy and $43(28.67 \%)$ had travel sickness.

In the course of study, the authors realized that the relation between the NVP severity during the third trimester and other risk factors might be worth looking at. A more detailed illustration of the subject is presented in Table 2.

The authors performed a statistical analysis of the material and it revealed that there is a relationship between the severity of NVP during the third trimester of pregnancy and the occurrence of nausea $(p=0.03)$ or vomiting $(p=0.02)$ in the course of previous pregnancies. There is a similar relationship in case of co-morbidities $(\mathrm{p}=0.02)$ and migraine headaches before pregnancy $(p=0.0007)$. Other variables did not influence the presence of scrutinized elements.

\section{DISCUSSION}

Nausea and vomiting may be one of the first signs of pregnancy. Various ailments affecting pregnant women can lead not only to bad mood but also frequent hospitalizations [1]. What is often referred to as the "morning sickness" might occur and prevail at any time during the day [2]. A research conducted by Jewell and Young [3] revealed that around 2\% of women are affected by NVP in the morning, whereas up to $80 \%$ of women reported some discomfort during the day. Its severity might differ although the symptoms tend to appear between $4^{\text {th }}$ and $9^{\text {th }}$ week of pregnancy, reaching its peak around $7^{\text {th }}$ to $12^{\text {th }}$ week, and subsiding around $16^{\text {th }}$ to $20^{\text {th }}$ week of pregnancy. Nevertheless, around $10 \%$ of women report such discomfort throughout the whole pregnancy [4-6]. A personal research somehow confirmed this conclusion as an approximate time of NVP appearance is week $7.45 \pm 3.47$. Its severity among respondents was mild or moderate, with a growing tendency of the former one, as symptoms intensified up to the third trimester of pregnancy. It should be noted, however, that subjects of the research were hospitalized due to different pregnancy complications and they were qualified for the investigation only on the basis of NVP occurrence.

A body of literature on the subject has found a link between the number of pregnancies and the severity of nausea and vomiting. Such thesis was confirmed by Chan et al. [7]. According to their research, NVP is more likely to happen to nulliparous. Similar results were obtained by Korzyścin et al. [6], yet they were not confirmed by Ebrahimi et al. [5]. Thesis was not been confirmed in this study, since the authors' personal research material did not reveal any major statistical differences in NVP severity among women in the first and in following pregnancies. 
TABLE 2. NVP severity rating including the impact of risk factors selected in the third trimester of pregnancy.

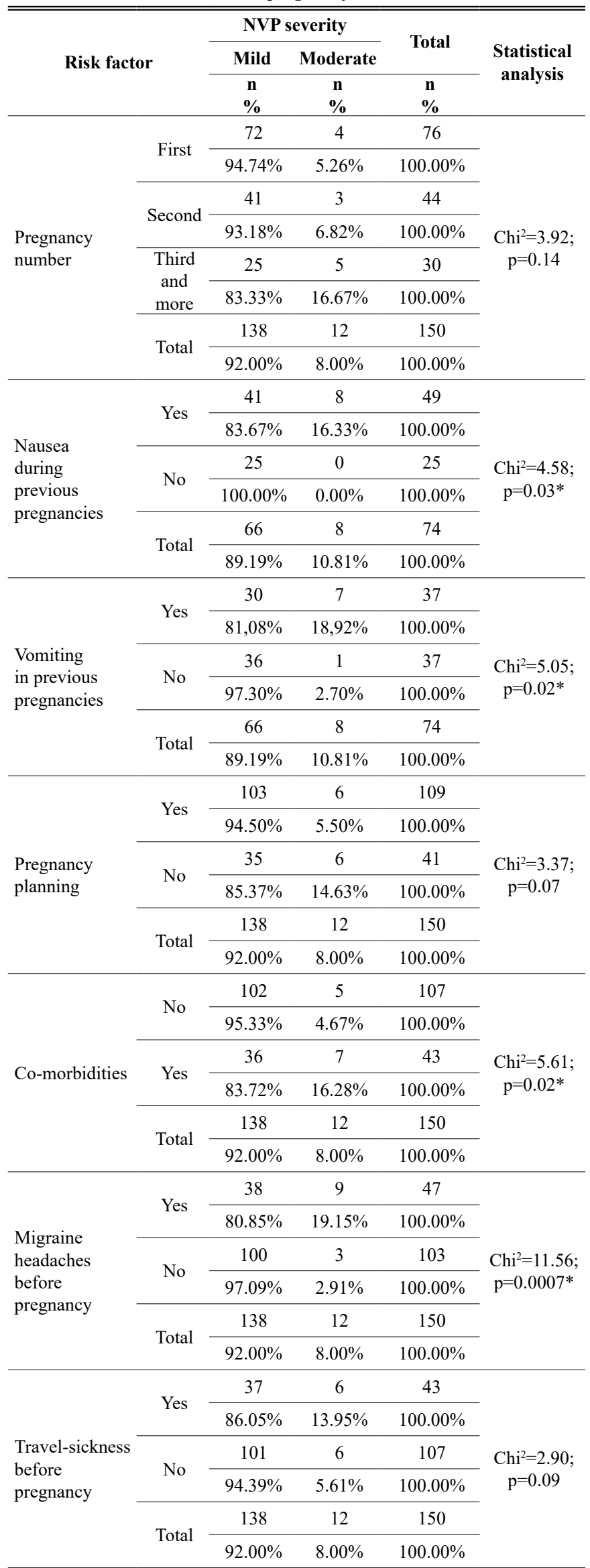

Sanu and Lamont [8] prove that the appearance on nausea and/or vomiting in the previous pregnancy may be one of the factors leading to the appearance of the pathology in following pregnancies. The same results were confirmed in personal research. It was stated that the respondents who had nausea in previous pregnancies did have them more often also during the next ones, reaching moderate severity in the third trimester. Similar relation was observed with regard to vomiting.

Various authors claim that NVP affects more often these women who have co-morbidities (i.e. related to liver, kidney, blood circulation or digestive problems). The analysis of personal research material revealed that gravidas who suffered from co-morbidities were affected by more severe symptoms of NVP in comparison to those who did not have any additional conditions.

NVP risk factors include as well pre-pregnancy travel-sickness and migraine headaches [9]. Gill et al. [10] proved that NVP affects more intensely women suffering from migraine headaches. Analyzed research material proves this statement partly. It was affirmed only statistically that there is an important relation between NVP and migraine headaches. However, no relation has been found with regard to travel-sickness.

Many a time, cases of nausea or vomiting are treated as a problem caused by psychosomatic disorders [6]. Usually, it is interpreted as a sign of stress and emotional tension related to the non-acceptance or even a rejection of pregnancy. Therefore, in the course of research it was studied if the NVP severity may have any connection with pregnancy planning by women. The analysis of the material revealed that women who planned pregnancy were affected more often by mild than moderate symptoms of NVP. However, differences between the groups were not statistically significant. As far as biological level is concerned, the scientists have not disclosed any satisfactory explanation concerning the etiopathogenesis of nausea and vomiting among gravidas, therefore, the pathogenesis should be looked for on psychological level. The scientists have agreed, however, that nausea and vomiting are the consequence of different factors and the concomitant stress, nuisance and constraints in everyday life may be the reason for bad mental state rather than the other way round $[11,12]$.

\section{CONCLUSIONS}

1. The severity of nausea and/or vomiting differs throughout pregnancy. Yet, in general terms moderate symptoms rather than mild occur in the first trimester while compared to the other trimesters of pregnancy.

2. Risk factors appearing before pregnancy (e.g. migraine headaches, nausea or vomiting) as well as co-morbidities have an impact on the severity of NVP affecting women in the third trimester of pregnancy. However, the number of pregnancies, whether they have been planned or not, as well as travel-sickness do not have any significance in this matter. 


\section{REFERENCES}

1. Sangidorj D. Zastosowanie akupunktury we współczesnym położnictwie. Ginekol Pol. 2006;77:485-91.

2. Festin M. Nausea and vomiting in early pregnancy. Clin Evid. 2009;06:1-3.

3. Jewell D, Young G. Interventions of nausea and vomiting in early pregnancy. Cochrane Database Sys. 2003;4:CD000145.

4. Basta A. Zmiany fizjologiczne w organizmie kobiety ciężarnej I ich znaczenie w praktyce lekarza ogólnego. Prz Lek. 2008;65(4):195-202.

5. Ebrahimi N, Maltepe C, Einarson A. Optimal management of nausea and vomiting of pregnancy. Int J Women`s Health. 2010:2:241-8.

6. Lee NM, Saha S. Nausea and vomiting in pregnancy. Arch Perinat Med. 2009;15(4):209-14.
7. Chan RL, Olshan AF, Sawitz DA, et al. Severity and duration on nausea and vomiting symptoms in pregnancy and spontaneous abortion. Hum Reprod. 2010;25(11):2907-12.

8. Sanu O, Lamont RF. Hyperemesis gravidarum: pathogenesis and the use of antiemetic agents. Expert Opin. 2011;12(5):737-48.

9. Bottomley C, Bourne T. Postępowanie w przypadku niepowściągliwych wymiotów u ciężarnych. Med Prakt Ginekol Poł. 2010;6:33-48.

10. Gill SK, Einarson A. The safety of drugs for the treatment of nausea and vomiting of pregnancy. Expert Opin. Drug Safety. 2007;6(6):685-94.

11. Brent R. Medical, social and legal implications of treating nausea and vomiting of pregnancy. AJOG. 2002;186:262-6.

12. Tkaczuk-Włach J, Robak-Chołubek D, Sobstyl M, et al. Niepowściągliwe wymioty ciężarnych. Prz Menopauz. 2007;5:310-5.

\section{Corresponding author}

Anna Cisek

21/41 Gęsia Str., 20-719 Lublin

E-mail: cisek.anna@wp.pl 